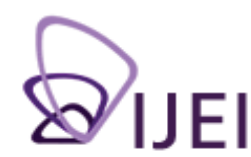

International Journal for Educational Integrity

\title{
Implications for academic integrity of using web 2.0 for teaching, learning and assessment in higher education
}

Jenny Waycott

Faculty of Medicine, Dentistry, and Health Sciences

The University of Melbourne

jwaycott@unimelb.edu.au

Kathleen Gray

Faculty of Medicine, Dentistry, and Health Sciences / Department of Information

Systems

The University of Melbourne

kgray@unimelb.edu.au

Rosemary Clerehan

Faculty of Medicine, Nursing and Health Sciences,

Monash University

Rosemary.clerehan@med.monash.edu.au

\section{Margaret Hamilton}

School of Computer Science and IT, RMIT University

Margaret.hamilton@rmit.edu.au

Joan Richardson

School of Business Information Technology, RMIT University

Joan.richardson@rmit.edu.au

Judithe Sheard

Faculty of Information Technology, Monash University

Judy.sheard@infotech.monash.edu.au

\section{Celia Thompson}

School of Languages and Linguistics, The University of Melbourne celiat@unimelb.edu.au

Keywords: web 2.0, assessment, academic integrity, student writing, higher education

\section{Abstract}

Student web 2.0 authoring in higher education involves a number of challenges and opportunities for assessment and academic integrity. In this article we describe an Australian project that is investigating how lecturers are using web 2.0 activities in university assessment tasks. In the first stage of the project we documented current web 2.0 assessment practices by conducting a survey and interviews with lecturers

The International Journal for Educational Integrity is available online at:

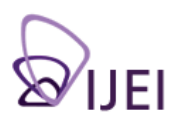


who teach in different discipline areas across Australia. Initial findings from this stage of the project are presented here, with a focus on using examples from the interviews to illustrate the opportunities and challenges that web 2.0 affordances introduce for learning, teaching, and assessment in higher education. Student authoring in web 2.0 environments can be quite different from traditional academic writing tasks. Using web 2.0 technologies, students can publish their work to an open audience, use different communication styles and texts, draw on their unique personal identity and experiences, co-create content with other students, and manage their content outside the confines of the university. Each of these affordances provides opportunities for enhancing students' learning in higher education, while simultaneously imposing new ways of thinking about scholarly writing and assessment that can be challenging for both students and staff.

\section{Background}

Student web 2.0 authoring - for example, blogging, microblogging, wiki writing, audio/ video podcasting, and social networking - is becoming a legitimate academic activity in many areas of higher education today. Several commentators have outlined convincing pedagogical rationales for encouraging students to undertake web 2.0 authoring activities as part of their university education (for example, Alexander, 2006; Boulos \& Wheeler, 2007; Huijser, 2008; Grosseck, 2009; McLoughlin \& Lee, 2008). In a web 2.0 environment, students can become "produsers" (Bruns, 2007), not only accessing and reading online information, but also creating, publishing and sharing content, reading and responding to their peers' writing, and collaborating to produce multi-authored texts. The possibilities for collaboration, communication, and creativity mean that web 2.0 activities are well-aligned with socio-cultural learning theories (McLoughlin \& Lee, 2007). In a recent review of web 2.0 in higher education in the UK, the potential benefits were summarised as follows:

e-Learning incorporating Web 2.0 offers the sense of being a contributing member of a learning community, which is one of the hallmarks of higher education. [...] Learning that is active - by doing - undertaken within a community and based on individual's interests, is widely considered to be the most effective. Driven by process rather than content, such an approach helps students become self-directed and independent learners. Web 2.0 is well suited to serving and supporting this type of learning. (Melville et al., 2009, p. 8)

However, not all commentaries about web 2.0, education, and scholarly writing have been positive (see Kakutani, 2010), and it is important to interrogate both the opportunities and challenges that may arise when students are asked to produce and share web 2.0 content as a formal part of their university education. Web 2.0 authoring in a scholarly environment has the potential to change the rules and standards of academic writing in higher education. A decade ago, Chodorow (2000) predicted that electronic publishing could potentially compromise authorship and scholarly integrity, expressing a concern that demands increasing attention from universities and the disciplines in today's web 2.0 world:

The form and substance of scholarly communications will change over time, so that it will be difficult to trace the historical flow of the work [...]. A free-flowing stream of scholarly discourse will reduce the role of scholarly authority in the progress of research [...] The roles of individual authors will be obscured in the electronic environment (Chodorow, 2000, p. 91).

Student web 2.0 writing may be quite different from the sort of writing that students are expected to do in a typical university essay assignment. For instance, students may be asked to write for a diverse and anonymous audience, to publish personal reflections that are open to review by peers, or to engage in whole-class collaborative 
writing projects. In this changing landscape there will be both opportunities and challenges for the advancement of student writing, academic integrity, and assessment standards. When web 2.0 authoring activities form part of students' assessment, it is particularly important that questions about appropriate assessment practices and academic standards in this environment are addressed.

In this article, we will briefly outline findings from a project, funded by the Australian Learning and Teaching Council, that aims to promote good practice in the assessment of student web 2.0 authoring in higher education. We will then describe five pedagogical affordances of student web 2.0 authoring and discuss both the opportunities and challenges that these affordances raise, using examples from our findings to illustrate the issues. The article will conclude with an overview of further project activities to date.

\section{Assessing student web 2.0 authoring: An ALTC Project}

The research reported here is part of a two-year project funded by the Australian Learning and Teaching Council (ALTC), "Web 2.0 authoring tools in higher education learning and teaching: New directions for assessment and academic integrity." A recent article published in the Australasian Journal of Educational Technology noted that while there are many published case studies demonstrating the use of web 2.0 (social web) technologies in higher education, these rarely contain details about how students' activities have been assessed (Gray et al., 2010). To date, little attention has been given in the peer-reviewed literature to issues relating to the assessment of students' social web activities - and the unique challenges and opportunities that this form of assessment may create for academic integrity, standards, and assessment practices. Our project aims to address this gap by: (i) examining and documenting current practice, (ii) identifying principles of good practice through national discourse about web 2.0 and assessment, (iii) reporting in-depth case studies of web 2.0 assessment activities, and (iv) producing guidelines and resources to support academics who are using, or planning to use, web 2.0 activities for medium to high-stakes assessment of student learning.

We adopted a participatory approach in this project, drawing on multiple academic experiences to identify the opportunities, challenges, and key issues that point to good practice in the assessment of student web 2.0 authoring (see Waycott et al, 2010 for more details). This involved, in the first stage, talking to lecturers about their experiences of using web 2.0 technologies in assessment activities. In September and October 2009 we conducted an online survey that asked respondents to provide details about one web 2.0 assessment task they had used in a subject they taught: that is, one graded piece of work in one subject or unit of study. The questions covered details about the way the assignment was designed and implemented, how it was marked, policy and procedure issues, and background information about the discipline and teaching context. Sixty-four Australian academics responded to the survey.

Initial findings from the survey have been summarised in a discussion paper (see Gray et al, 2009) and are currently being analysed for further dissemination. The survey showed that while a variety of web 2.0 activities are being used in Australian higher education, the most common activities are wiki writing and blogging $(50 \%$ and $48 \%$ of respondents, respectively, said their assignment involved these activities), both of which highlight questions of individual identity in new forms of student writing. Respondents came from a cross-section of disciplines, the most highly represented being: humanities ( $42 \%$ of respondents), information technology (32\%), and education $(30 \%)$. 
In a series of questions that used Likert-scale ratings, participants were asked to indicate how well their assignment catered to a number of academic policy issues, that is, factors that ensured the assignment was conducted fairly for all students. Overall, most participants indicated that their assignments did address all major policy issues. However, a large minority indicated that they were uncertain whether their assignment addressed key policy issues that were closely related to concerns about scholarly writing, authorship, and academic standards in a web 2.0 environment. For instance, $20 \%$ of survey respondents answered "not sure" when asked if their assignment encouraged academic honesty and integrity. Twenty-seven per cent of respondents were unsure if students' moral rights and copyright in work they produced were protected, while $28 \%$ were not sure whether students whose work showed evidence of cheating or misconduct were formally disciplined.

In order to provide more in-depth information about these and other issues, we conducted follow-up telephone interviews with 22 survey respondents. The interviews provided information about lecturers' teaching and assessment practices and insight into their perspectives on the use of web 2.0 activities in university teaching. Examples of some of the issues that interviewees identified are provided in the following section on affordances of web 2.0 authoring for teaching, learning, and assessment in higher education.

\section{Pedagogical affordances of web 2.0 authoring in higher education}

The term 'affordances', which has a history in human-computer interaction research (Norman, 1998), has been used in educational technology literature to denote the possibilities that web 2.0 technologies and activities offer when they are used to support learning in higher education (e.g., McLoughlin \& Lee, 2008). Using web 2.0 technologies does not guarantee that these possibilities will be realised. According to McLoughlin and Lee, the affordances of web 2.0 in higher education depend on the users' (or learners') perspectives and how they interpret the task and the tools they are using. Furthermore, "how learners perceive the possibilities of the tools ... may be markedly different to the ideas and intentions of the educators and educational technologists who design them" (McLoughlin \& Lee, 2008, p. 11).

Drawing on our discussions with lecturers, as well as the survey findings and the proceedings of a national roundtable event (see Waycott et al, 2010, for an overview), we identified five affordances of web 2.0 authoring for teaching, learning, and assessment in higher education: 1) open publishing, 2) new communication styles and texts, 3) expressing personal identity and experience, 4) co-creation and collaboration, and 5) content management. These affordances illustrate what is unique or unusual about student authoring in a web 2.0 environment and raise both opportunities and challenges for educators intending to assess student web 2.0 authoring in higher education.

\section{Open publishing}

One of the key affordances of web 2.0 technologies is the opportunity for users to create and share content in an open forum. Using tools such as blogs, wikis, and social networking sites, students can publish their work for a broad, and potentially anonymous, audience, which raises risks of potential appropriation and issues of privacy. We spoke to lecturers who described assignments in which students kept public blogs or contributed to a wiki that was openly available for an external audience to see. This open publishing added to the authenticity of the task, creating a real audience for students. In one example, students in a cultural studies subject maintained a blog that included music reviews. The lecturer noted: 
It was not unusual for the musician or his manager or someone to make a comment on the blog and to correct misinformation or thank them for an opinion or whatever, and I think that is a really important lesson for [students] to learn that whatever they write they're writing for an audience and, if they're writing for more than an audience of one, that has implications.

In some cases, students' work was visible only to other students and lecturers. It was, therefore, not open to the scrutiny of an external audience, but was made visible for other students to review and respond to, with the aim of fostering a cooperative learning environment and creating opportunities for students to develop their critical analysis skills through reviewing and commenting on their peers' work. While the lecturers we spoke to noted these positive implications of open publishing, they also highlighted potential risks and challenges. For instance, some students appeared to be hesitant about publishing their work. Lecturers attributed this to a fear that other students might copy their work: "I know one or two of the very High Distinction [students] tend to hold off posting their work, right up until the deadline. I know they've done it because they don't want others to copy them."

In addition, there were concerns about the ethical implications of asking students to publish their work on the World Wide Web. Lecturers addressed these concerns by ensuring that their students were aware of the risks: "I am conscious that it does expose students' work before it's assessed ... I tell the students over and over again that it is on the World Wide Web, it's not associated with the university, be careful what you put up there, make sure you are comfortable with this." Students were also, in some cases, given the option of publishing their work anonymously, creating a safety net for those who did not feel comfortable with being identified as the authors of work published on the web.

\section{New communication styles and texts}

The style of writing in a web 2.0 environment can be quite different from the academic style that students might expect to use in other university assignments. This may be due, in part, to open publishing: students need to adapt their communication style when writing for a real, yet unknown, audience. The use of different styles of writing and communication is also implicit in the design of many web 2.0 technologies. For instance, blogging tools can be used as online journals, with pages displayed chronologically, and features that enable authors to link to other online content and embed multimedia within each entry. Writing a blog might involve creating frequent short pieces of work combining audio, video, images, and text. In addition, the personal nature of blogging (and other web 2.0 activities) can foster an informal, conversational style of writing, raising questions about the place of web 2.0 writing in relation to scholarly writing. For some lecturers this affordance was a key reason for incorporating a web 2.0 assignment in their subject: "It's not a formal writing exercise, the idea is to let them express their thoughts, reflections, interests in the different topics rather than focusing on good grammar and formal sentence structure, which I think tends to constrain a lot of essays."

For others, the different communication styles and texts in web 2.0 authoring made assessment more arduous. One lecturer remarked that "because the content does not have to be of an academic standard it can be hard (to) assess, e.g., marking sloppy/ lazy prose". Another lecturer found that students' web 2.0 assignments included numerous links to other material and media, so that tutors had to assess "a whole labyrinth of choices and connections."

Lecturers also found that students needed a lot of support and guidance when faced with the task of producing a university assignment using different communication 
styles and texts. Students typically knew how to approach more traditional assessment tasks ("If you ask them to write an essay they just go off and write it; you don't have to spend the first three weeks of the course teaching them about essays"). With web 2.0 authoring, however, students needed to be reassured that they were doing the right thing: "Since a lot of the students had no experience with this as an assessment task they needed feedback on what's working, what's not working, how they can improve, how they can build". So while many lecturers hoped to use web 2.0 activities to enable and encourage their students to employ different communication styles and texts, they faced a number of challenges in designing, managing, and marking assignments that made use of this affordance.

\section{Expressing personal identity and experience}

In a web 2.0 environment students also have the opportunity to create a distinct online identity using, for example, profiles, avatars, and favourites. They can also create and publish content that draws on their personal experiences, challenging old conceptions of the need to induct students into certain kinds of disciplinary writing. Students' online identity can be different from the student who is recognisable in class, which may encourage some students to participate more actively than they would in classroom discussions. Many of the lecturers we spoke to suggested that web 2.0 activities enabled all students, including those who would normally be reluctant to participate in class, to have a "voice": "I think one of the most obvious benefits is that it allows all the students to have a voice and it allows me to recognise that they've all got a voice because not all of them will speak up in class and not all of them will function well with the formal writing tasks".

Students' social or cultural experiences of web authoring can influence the work they produce in web 2.0 assignments. In addition, many web 2.0 assignments are designed to encourage students to reflect on their personal experiences and to draw on their identities outside the classroom. For instance, one lecturer we spoke to described an assignment in which postgraduate education students used web 2.0 tools to share and reflect on their professional experiences. Students were able to "share something of their own world ... A lot of them brought in photos or talked about their learning context, which as a teacher doesn't always happen".

Through writing and publishing web 2.0 content, students learn to create and express an online identity. One lecturer observed that as her students progressed in their public blogging assignment, they developed an increasingly confident online voice and identity. Students needed to overcome inhibitions and doubts in order to develop this voice: "There's a sort of process that goes into them finding their different voices, how to share appropriately, how to write with authority. ... Some of them never get it; others can take three or four weeks to find their voice". In this example, students' work was published openly and the lecturer noted that there was conflict, for some students, between their identity as students and their identity as web 2.0 authors: "Some will always write, even at the end, 'I'm just a student, I've got no point of view', so there are identity issues. But that's becoming less of an issue these days than it was because people have more presence online". In other words, as students become more experienced at creating and presenting online identities in their personal and professional lives, they may become more comfortable crafting an online voice and identity as part of their university coursework.

On the other hand, however elaborate and compelling students' online identities and experiences are, they must be authenticated for the purposes of assessment. If students are posting their work anonymously this means lecturers need to know the pseudonyms that each student is using. One lecturer noted: "I let them choose their own names but I did provide a page where they had to enter the name that they were using and their student number ... Before they could start editing, they had to put in their username, Funky Monkey [for example] and their student number". In larger 
classes lecturers may need to have more control over students' online identities for the purposes of authentication. One lecturer, for instance, took portrait photographs of her students, which they then uploaded as their profile photos: all students' contributions to the shared web 2.0 space could then be immediately identified.

\section{Co-creation and collaboration}

One of the key features of web 2.0 authoring is the facility for multiple authors to contribute to the content. Collaborative authoring in a web 2.0 environment can scale between a small closed group and a large free-to-join learning community. With largescale collaborations, content can be built on "collective intelligence":

One of the fundamental ideas underlying Web 2.0 [is] that successful network applications are systems for harnessing collective intelligence ... a large group of people can create a collective work whose value far exceeds that provided by any of the individual participants. (O'Reilly \& Battelle, 2009)

University web 2.0 assignments may not involve the international collective intelligence seen in the development of resources such as Wikipedia, but they can involve collaborative authoring on a larger scale than students and staff may be used to. We spoke to lecturers who had implemented assignments in which all students enrolled in the subject contributed content to a shared resource. This meant that students shared the ownership of the work, which one lecturer viewed as a positive outcome: "The biggest plus for me was having an activity that had ownership by the whole group as opposed to the individual tutorial groups. [It acted] as a unifying sort of focus to get students involved with each other".

However, some lecturers found large-scale collaborative authoring difficult to manage and assess. Using a wiki, students could comment on, add to, or delete other students' contributions, and this appeared to be confronting for some students: "They saw what they had typed in and their lovely wiki page being changed by somebody else. There were some instances where whole sentences or paragraphs were being removed". As one lecturer noted, this created a unique challenge for assessment: "How do you mark assignments when students can change/overwrite each other's work! Many students who contributed early found that their work was completely lost. How do you manage this process of overwriting and still contributing to the same content?"

There were, however, some lecturers who used the features of web 2.0 tools to view the history of the work to see who had contributed content over time. While some web 2.0 tools made it possible to view individual contributions to a shared resource, in assignments that involved large-scale collaborations, this was still a time-consuming and difficult process for the lecturers or tutors marking the work.

\section{Content management}

In web 2.0 assignments, students' assessable work may consist of remixing preexisting web content from diverse sources, raising questions about how this content may be controlled, and managed over time. Students' work can also be posted on several host sites, and work posted on one site may be syndicated by others and tracked back. When using freely available web 2.0 tools, external to the university's enterprise systems, students control (or cede control of) the content they produce for assessment in accordance with terms of service, end user agreements or other governance policies of host sites. In some cases, this may mean students have more control and flexibility over their content than they would in other university assignments. For instance, students may choose to continue writing a public blog 
after the blogging assignment has been completed. In many web 2.0 environments, students have access to an archive of their work, creating an electronic portfolio they can show to potential employers or use to reflect on their learning. One lecturer described an assignment in which her students posted their work on a social networking site. This meant students and lecturers had constant access to the work students produced over the course of the semester: "Normally they will do an assignment, you will mark it, you give it back to them and it gets thrown under their bed ... [this way] it is there all the time for them to reflect on and it is there for us to look back on what they did in their last assignment to see if they have improved".

In other assignments, students created content that was then removed from the web or moved to a space that students could no longer access, giving students no control over the ongoing management of the content. In one case, students created content for a shared wiki that was then used as a learning resource for other students on the course. The lecturer commented that while this was a successful learning activity, managing the wiki after students had completed the assignment, and ensuring the information remained accurate and up-to-date, was a continuing challenge for staff:

There's an ongoing debate about the accuracy of the information. Are we satisfied that because it passes as an assignment it should go out there and what happens if it becomes out of date? ... It's okay for the student notes to be private and have errors in them but if we start making a public resource like this what happens if it's got errors in it? That's one of the reasons why at the moment we're locking it once it's been assessed but even so you've got the 'going-out-of-date' problem and one of the things l'd like to do would be to have it as an ongoing editable document with staff and students editing it.

While there are clearly advantages to allowing students to have control over the ongoing management of the web 2.0 content they create in their university work, this may not be possible or appropriate for all assignments. When designing web 2.0 assignments, then, lecturers need to consider how content will be managed over time.

\section{Further project activities and resources}

The affordances described above encompass some of the challenges and opportunities that web 2.0 activities offer for student writing and assessment in higher education. These were identified during the initial stages of our project, which involved documenting current web 2.0 assessment practices and initiating national discourse about web 2.0 and assessment. Drawing on these findings and discussions, we developed a draft framework of good practice for web 2.0 assessment in higher education (Gray et al, 2010). The affordances described above were incorporated into this document, in a series of checklists that encouraged academics to consider how and why they were using web 2.0 for assessment. This draft framework was then used as the basis for data collection in a series of case studies that involved closely examining web 2.0 assessment practices in a range of higher education settings (see Table 1). 
Table 1:

Overview of case studies

\begin{tabular}{|c|c|}
\hline Social web activity & Subject/Discipline \\
\hline Blogging & $\begin{array}{l}\text { Criminal Law } \\
\text { Cultural Studies } \\
\text { Cinema Studies } \\
\text { Media Studies }\end{array}$ \\
\hline Social bookmarking & Education \\
\hline Social networking & Languages \\
\hline Photo sharing & Communication Design \\
\hline Vodcasting & $\begin{array}{l}\text { Economics } \\
\text { Business }\end{array}$ \\
\hline Virtual worlds & Languages \\
\hline Wiki writing & $\begin{array}{l}\text { Accounting } \\
\text { Education } \\
\text { Science } \\
\text { Information Technology } \\
\text { Languages }\end{array}$ \\
\hline Combined Web 2.0 tools & $\begin{array}{l}\text { Information Management } \\
\text { Information Technology }\end{array}$ \\
\hline
\end{tabular}

The case studies were conducted in Semester 12010 and aimed to field-test ideas for good practice in web 2.0 assessment in higher education, as well as facilitating a participatory approach to implementing change and improving practice. The 17 case studies covered a range of disciplines and web 2.0 activities. They were conducted as ethnographic studies involving regular meetings with participating lecturers over the semester, observations of classroom and assessment activities where possible, and collection of assessment artefacts. In addition, participating lecturers had the opportunity to engage in dialogue with other participants during introductory workshops at the beginning of the semester and during reflective focus group sessions at the conclusion of the case studies. Focus group sessions with students were also held.

\section{Conclusion}

Student web 2.0 authoring in higher education involves a number of challenges and opportunities for assessment and academic integrity. When creating web 2.0 content, students may be able to publish their work to an open audience, use different communication styles and texts, draw on their unique personal identity and experiences, co-create content with other students, and manage their content outside the confines of the university. While each of these affordances provides opportunities for enhancing students' learning in higher education, they also impose new ways of thinking about scholarly writing and assessment that can be challenging for both 
students and staff. As part of our ALTC funded project we have been examining these issues with the aim of producing and sharing resources to support academics who are using web 2.0 activities in higher education assessment. These resources will be disseminated in Australia in early 2011. When the project resources are available, further information about how to access them will be published on the project website: http://www.web2assessment.blogspot.com.

\section{References}

Alexander, B. (2006). Web 2.0: A new wave of innovation for teaching and learning? Educause Review, 2006(March/April), 33-44.

Boulos, M. N. K., \& Wheeler, S. (2007). The emerging web 2.0 social software: An enabling suite of sociable technologies in health and health care education 1. Health Information and Libraries Journal, 24(1), 2-23.

Bruns, A. (2007). Produsage: Towards a broader framework for user-led content creation. In B. Shneiderman (Ed.), Proceedings of the 6th ACM SIGCHI Conference on Creativity \& Cognition (pp. 99-105). New York: ACM Press.

Chodorow, S. (2000). Scholarship and scholarly communication in the electronic age. Educause Review, 35(1), 86-92. Retrieved 28 November, 2007 from http:// www.educause.edu/ir/library/pdf/ERM001B.pdf

Gray, K., Thompson, Sheard, J., Clerehan, R., \& Hamilton, M. (2010). Students as web 2.0 authors: Implications for assessment design and conduct. Australasian Journal of Educational Technology, 26(1), pp. 105-122.

Gray, K., Waycott, J., Clerehan, R., Hamilton, M., Richardson, J., Sheard, J. \& Thompson, C. (2009). Web 2.0 authoring tools in higher education learning and teaching: New directions for assessment and academic integrity. Discussion paper for National Roundtable on 23rd November 2009. Retrieved $9^{\text {th }}$ December 2010 from http://web2assessmentroundtable.pbworks.com/f/ ASW2A+Discussion+Paper.pdf

Gray, K., Waycott, J., Clerehan, R., Hamilton, M., Richardson, M., Sheard, J. \& Thompson, C. (2010). Web 2.0 authoring tools in higher education learning and teaching: New directions for assessment and academic integrity. A framework for field-testing and refining good practice guidelines in pilot projects at Australian universities during Semester One 2010. Retrieved 12 August, 2010 from http://web2assessmentroundtable.pbworks.com/f/ALTC-ASW2AGuidelines-draft-Feb2010.pdf

Grosseck, G. (2009). To use or not to use web 2.0 in higher education? Procedia Social and Behavioral Sciences 1, 478-482.

Huijser, H. (2008). Exploring the educational potential of social networking sites: The fine line between exploiting opportunities and unwelcome imposition. Studies in Learning, Evaluation Innovation and Development, 5(3), 45-54.

Kakutani, M. (2010, 17 March). Texts without context. [Book review]. New York Times. Retrieved June 12, 2010 from http://www.nytimes.com/2010/03/21/ books/21 mash.html?ref=books

McLoughlin, C. \& Lee, M. J. W. (2007). Social software and participatory learning: Pedagogical choices with technology affordances in the Web 2.0 era. In ICT: Providing choices for learners and learning. Proceedings ascilite Singapore 2007. http://www.ascilite.org.au/conferences/singapore07/procs/mcloughlin.pdf

McLoughlin, C., \& Lee, M. J. W. (2008). Mapping the digital terrain: New media and social software as catalysts for pedagogical change Hello! Where are you in the landscape of educational technology? Proceedings ASCILITE Melbourne 2008, pp. 641-652.

McLoughlin,C., \& Lee, M. J. W. (2008). The three Ps of pedagogy for the networked society: Personalization, participation, and productivity. International Journal of Teaching and Learning in Higher Education, 20(1), 10-27. 
Melville, D., Allan, Cl., Crampton, J., Fothergill, J., Godfrey, A., Harloe, M., et al (2009). Higher Education in a Web 2.0 World: Report of an independent Committee of Inquiry into the impact on higher education of students' widespread use of Web 2.0 technologies. Retrieved February 25, 2010, from http://www.jisc.ac.uk/publications/generalpublications/2009/heweb2.aspx

Norman, D. A. (1998). The invisible computer: Why good products can fail, the PC is so complex, and information appliances are the answer. Cambridge, MA: MIT Press.

OReilly, T., \& Battelle, J. (2009). Web Squared: Web 2.0 Five Years On. Special Report for the Web 2.0 Summit, 20-22 October, San Francisco CA. Retrieved November 1, 2009 from http://assets.en.oreilly.com/1/event/28/ web2009 websquared-whitepaper.pdf

Waycott, J., Gray, K., Thompson, C., Sheard, J., Clerehan, R., Richardson, J., \& Hamilton, M. (2010). Transforming assessment in higher education: A participatory approach to the development of a good practice framework for assessing student learning through social web technologies. In C.H. Steel, M.J. Keppell, P. Gerbic \& S. Housego (Eds.), Curriculum, Technology and Transformation for an Unknown Future. Proceedings ascilite Sydney 2010 (pp.1040-1050). http://ascilite.org.au/conferences/sydney10/procs/Waycottfull.pdf

\section{Acknowledgements}

We would like to thank the academics who responded anonymously to our survey and the many lecturers who have participated in our field-testing. Support for this project has been provided by the Australian Learning and Teaching Council Ltd, an initiative of the Australian Government Department of Education, Employment and Workplace Relations. The views expressed in this paper do not necessarily reflect the views of the Australian Learning and Teaching Council.

\section{About the authors}

Jenny Waycott is a researcher in educational technology at the University of Melbourne and is project manager on the ALTC-funded project, "Web 2.0 authoring tools in higher education learning and teaching: New directions for assessment and academic integrity". Kathleen Gray is the project leader and is a Senior Research Fellow in Health Informatics in the Faculty of Medicine, Dentistry and Health Sciences, at the University of Melbourne. Rosemary Clerehan is Associate Professor and Director of the International Postgraduate Academic Support unit in the Faculty of Medicine, Nursing and Health Sciences at Monash University. Margaret Hamilton is a Senior Lecturer in the School of Computer Science and IT at RMIT University. Joan Richardson is the Deputy Director of Teaching and Learning in the School of Business Information Technology at RMIT University. Judy Sheard is a Senior Lecturer and Director of the MIT and MNC (minor thesis) degrees in the Faculty of Information Technology at Monash University. Celia Thompson is the Coordinator of English as a Second Language (ESL) and Intensive Academic Program in the School of Languages and Linguistics at the University of Melbourne. The authors are all members of the project team working on the ALTC-funded project "Web 2.0 authoring tools in higher education learning and teaching: New directions for assessment and academic integrity". More information about the authors can be found at: http:// web2assessment.blogspot.com/p/project-team.html 